\title{
An optimal period for setting sustained variability levels
}

\author{
PATRICIA D. STOKES and PETER BALSAM \\ Barnard College of Columbia University, New York, New York
}

\begin{abstract}
In two experiments, we investigated how explicit reinforcement of highly variable behavior at different points in training affected performance after the requirement was eliminated. Two versions of a computer game, differing in the number of possible solution paths, were used. In each, an optimal period of training for producing sustained high variability was found. Exposure to a high lag requirement shortly after acquisition sustained variability. Rewarding variability at other times did not have a sustained effect. The implications for learning and problem solving are discussed.
\end{abstract}

High levels of variability are associated with giftedness (Janos \& Robinson, 1985; Winner, 1996) and creativity (Root-Bernstein, Bernstein, \& Garnier, 1995; Stokes, $1999 \mathrm{~b}$; Wallace \& Gruber, 1989), as well as with greater learning (Alibali \& Goldin-Meadow, 1993; Graham \& Perry, 1993) and readiness to learn (Keil, 1984; Klahr, 1984 ) in children. For example, a greater number of correct answers on Piaget's number conservation task came from children who gave more explanations for their answers during both pretests and experimental trials (Siegler, 1995). Activation of multiple, often competing, hypotheses or strategies has been shown to signal children's readiness to acquire novel concepts (Goldin-Meadow, Nusbaum, Garber, \& Church, 1993).

Given these kinds of effects, an important issue is ifand how-habitual (i.e., sustained) individual differences in variability are learned. Most work on variability has not addressed this issue, since it has been concerned with the immediate effects of schedules of reinforcement or variability requirements on responding. As a result, we know that variability tends to decline during response acquisition (Antonitis, 1951; Schwartz, 1982a, 1982b; Vogel \& Annau, 1973) and, as compared with continuous reinforcement, to increase during extinction or intermittent reinforcement (Eckerman \& Lanson, 1969; Tatham, Wanchisen, \& Hineline, 1993). We also know that variability increases when reward is contingent on doing something new (Holman, Goetz, \& Baer, 1977; Pryor, Haag, \& O'Reilly, 1969) or doing something differently (Joyce \& Chase, 1990; Maltzman, 1960; Neuringer, 1992, 1993; Royce, 1898; Ryan \& Winston, 1978). The greater the difference from prior responding required, the higher the variability (Machado, 1992, 1997; Page \& Neuringer, 1985; Stokes, 1999a).

The authors thank Helen Harrison, Alanna Mulhern, and Susan Farkas for collecting and analyzing data. Address correspondence to P. D. Stokes, Department of Psychology, Barnard College, Columbia University, New York, NY 10027 (e-mail: pstokes@barnard.columbia.edu).
Far fewer studies have looked at the lasting effects of early training (i.e., effects seen after the generating contingencies are removed) on sustained levels of variability, despite the fact that initial learning has effects on many aspects of later performance, including topography (Stokes \& Balsam, 1991), rate (Weiner, 1969), and persistence (Eisenberger, 1992). As coaches and teachers who exhort students to learn it "right the first time" know, early learning can either facilitate or interfere (Atwood \& Polson, 1976; Duncan, 1958; Luchins, 1942; Moxley, 1979; Schmidt \& Bjork, 1992; Schwartz, 1982a; Shea \& Morgan, 1979) with subsequent acquisition on variants of the original task.

Some studies have documented the effects of different types of early training on variability, although this was not their express purpose. Development of stereotyped sequences interfered with college students' discovering the correct rule for earning points, and acquisition of higher order stereotypy (repeating sequences in a set pattern) precluded subsequent production of novel sequences (Schwartz, 1982a, 1982b; but see Wong \& Peacock, 1986). ADHD and normal children who initially had to respond variably continued to do so when variability was no longer required (Saldana \& Neuringer, 1999).

Other studies were designed to examine the effects of different types of early training. As compared with children rewarded simply for completing a task, those initially rewarded for novelty or originality were more variable during that task and on a subsequent, nonrewarded one (Eisenberger \& Armeli, 1997). Rats trained to barpress under a strict topographic constraint (right paw only) were more variable than rats trained under a lenient constraint (press any way), both during the initial constraint and much later, when the constraints were reversed (Stokes, 1995). In a task in which college students were exposed to a sequence of monotonic changes in variability requirements, participants who began training with a high variability requirement were more variable at each stage of training than those participants who started with a low variability requirement (Stokes, 1999a). Students exposed to a large 
increase in response requirements soon, but not immediately, after the start of training sustained higher variability levels than did those exposed to the same shift earlier or later (Stokes, Mechner, \& Balsam, 1999).

These studies led us (Stokes, 1999a; Stokes et al., 1999) to suggest an early critical or optimal period during which sustained variability levels are selected. Although changing response requirements at any time augments variability, Stokes et al. showed that high variability levels are sustained only when such a shift is introduced shortly after the rudiments of a task are learned. In their study, reward did not depend on variability. Rather, higher variability levels accompanied changes in explicit response requirements. Since variability seems to have been inadvertently reinforced, implicit variability criteria were said to be in effect. The present experiments tested this hypothesis by manipulating explicit variability criteria.

The level of variability was specified by a lag contingency giving the number of prior response sequences from which a current sequence must differ. For example, in a task requiring a three response sequence consisting only of responses $\mathrm{A}$ and $\mathrm{B}$, a lag2 requirement would be met if the current sequence (e.g., AAA) differed from the two immediately prior sequences (e.g., ABA, BBA). The present experiments used just such a task. Called a pyramid game, it involved pressing the left and/or the right arrow key to move a lighted diamond from the apex to the base of a triangle (Boulanger, 1990; Tatham et al., 1993).

\section{EXPERIMENT 1}

Experiment 1 used a pyramid game in which each path from the apex to the base required 10 left and/or right arrow keypresses. Identically high levels of variability were required at two different points in training. In one group, a lag 25 requirement was in effect between the 1st and the 50th reinforced trials. For a second group, it was in effect between the 51st and the 100th trials. At all other times, there was no variability requirement. A third, control group had no explicit variability requirement.

If higher levels of sustained variability result from reinforcing highly variable responding shortly after acquisition, the group exposed to the lag contingency during the second block would be the most variable later, when no lag requirement was in effect.

\section{Method}

Participants. Thirty female Barnard undergraduates participated to fulfill an introductory psychology class requirement.

Apparatus and Stimuli. Ten personal computers, in separate $1.5 \times 3.5 \mathrm{~m}$ experimental rooms, were used for stimulus presentation and data collection. The door to each room was shut in order to attenuate noise. Figure 1 presents the pyramid display. Superimposed on the pyramid was a grid with a white start box at the top and alternating red and blue diamonds between the white box and the bottom row of orange triangles, which were the end points. The participants could press the left or the right directional arrow key to move the white box through the pyramid. For the pyramid shown in Figure 1, a total of 10 presses, on the right or the left key, moved the box from its starting position to one of the 11 orange triangles at the

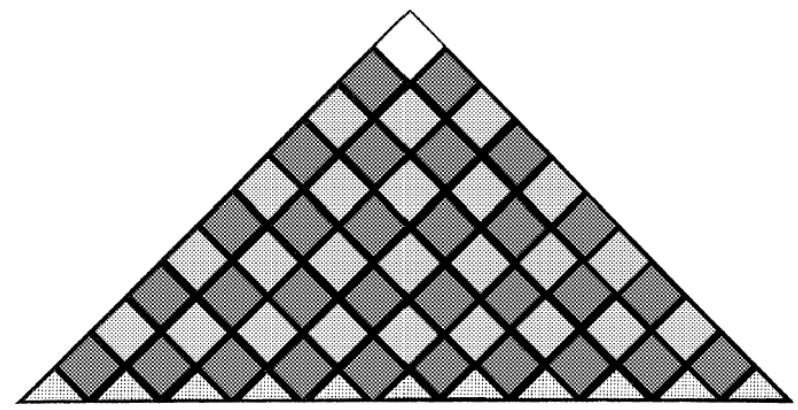

Figure 1. Screen display for the 10-pyramid.

bottom. When a sequence of presses met a contingency, the pyramid disappeared, and the words " 1 point" plus a cumulative total of points earned appeared, accompanied by a beep. Since 10 presses were required, the pyramid displayed is called a 10-pyramid. It has 1,024 different press sequences (paths).

Procedure. There were three groups (first, second, and control). The names reflect whether or not a group was exposed to the lag25 requirement and when the requirement was imposed. Table 1 shows the lag requirements for each group in five successive blocks of 50 reinforced trials. During lag0, the current path did not have to differ from any prior path. Since the contingency reset at the start of each block, the lag 25 contingency was based only on sequences emitted during that block-regardless of when it was introduced. Consequently, during the lag25 block of trials, the number of prior paths from which a current path had to differ increased from 0 on the trial to 25 on all trials after the 25 th trial. That is, the first trial during lag25 was always reinforced, the second trial was reinforced only if it differed from the first, the third trial only if it differed from the first and second, and so forth. After the 25 th trial, each sequence had to differ from the previous 25 in order to earn points.

The control group was only exposed to the lag0 requirement. The first group experienced the lag25 contingency during the first block (1st to 50th reinforced trials); the second group experienced the identical contingency during the second block (51st to 100th reinforced trials). Two hundred and fifty points were earned for correct sequences. There was a short break (about $2 \mathrm{~min}$ ) between the 200th and the 201st reinforced trials.

The instructions were the following: "The purpose of this experiment is to see how simple motor tasks are learned. You have been assigned to a group that gets feedback from the computer. Your task is to earn points by generating keypress sequences. You can use two keys - the left and right directional arrows. After a correct sequence, a point will appear on the screen. During the experiment, the sequences that earn points may change. If this happens, you may have to alter your pressing patterns. You may not hold keys down for long periods of time. You must press a key and let it go. Otherwise, we won't be able to use your data."

There was no time limitation. The participants were debriefed at the end of the experiment.

Statistical analyses. The data were divided into blocks. In each block, 50 reinforcers were delivered. Since incorrect paths were possible during the lag25 contingency, more than 50 trials were often necessary to earn the 50 reinforcers. For purposes of analysis, only the last 50 trials in each block were included. Variability was assessed by examining the number of different paths (10 press sequences) taken through the pyramid in a given block. A signif icance level of $p<.05$ was used.

To examine group differences during and following the experimental manipulation, mixed two-way analyses of variance (ANOVAs), with group ( first, second, control) and block as factors, were run on data from four successive 50-trial blocks. For the lag groups, the 
Table 1

Block-by-Block Lag Requirements

\begin{tabular}{lrrrrrrr}
\hline & \multicolumn{7}{c}{ Blocks } \\
\cline { 2 - 7 } Groups & 1 & 2 & 3 & 4 & 5 & 6 & 7 \\
\hline Experiment 1 & & & & & & & \\
Control & 0 & 0 & 0 & 0 & 0 & & \\
First & $\mathbf{2 5}$ & 0 & 0 & 0 & 0 & & \\
$\quad$ Second & 0 & $\mathbf{2 5}$ & 0 & 0 & 0 & & \\
Experiment 2 & & & & & & & \\
Control & 0 & 0 & 0 & 0 & 0 & 0 & 0 \\
First & $\mathbf{2 5}$ & 0 & 0 & 0 & 0 & 0 & 0 \\
Second & 0 & $\mathbf{2 5}$ & 0 & 0 & 0 & 0 & 0 \\
Fourth & 0 & 0 & 0 & $\mathbf{2 5}$ & 0 & 0 & 0 \\
\hline
\end{tabular}

Note-Lags greater than 0 are indicated in boldface.

initial block was the one in which the lag25 contingency was in effect. The control group was matched to the second group, so the four blocks for this group began on the 51st reinforced trial. Fisher's least significant difference (LSD) test was used for post hoc comparisons.

\section{Results}

Figure 2 presents mean number of different paths for each group during the four successive blocks. There was a significant main effect of block $[F(3,25)=13.32, p<$ $.01]$, and a group $\times$ block interaction $[F(6,52)=2.40$, $p<.05]$. That interaction resulted, in part, from a significant group $\times$ block interaction $[F(3,16)=3.23, p<.05]$ found for the two lag groups. The effect of group was marginal $[F(2,27)=2.72, p=.08]$. LSD tests, comparing each group with each other group at each block, showed that during the block in which the first and second groups were exposed to the lag25 requirement, the two groups were not significantly different from each other ( $p=.626)$ and were more variable than the control group (for both comparisons, $p<.01$ ). The second group was significantly more variable than either the first ( $p=$ $.05)$ or the control $(p<.05)$ group in the fourth block.

To make sure that these results did not follow from the group differences prior to or during the lag manipulation, number of different paths was compared in the two groups that started training without the lag contingency in effect. These did not differ significantly during the first trial block $[t(18)=0.67]$. Group means were 28 for the control group and 32 for the second group. Both groups were rewarded $100 \%$ of the time during this block. As was shown by the LSD tests ( $p=.626$ ), the lag groups did not differ during the lag 25 contingency in number of different paths. They also did not differ in percentage of reinforced trails during the whole block $[t(18)=0.15]$. Group means were 39.2 paths for the first group, $70 \%$ reinforced, and 41.1 paths for the second group, $78 \%$ reinforced. As would be expected from this lack of difference in percentage of reinforced trials, there was also no difference in total number of trials $[t(18)=1.32]$.

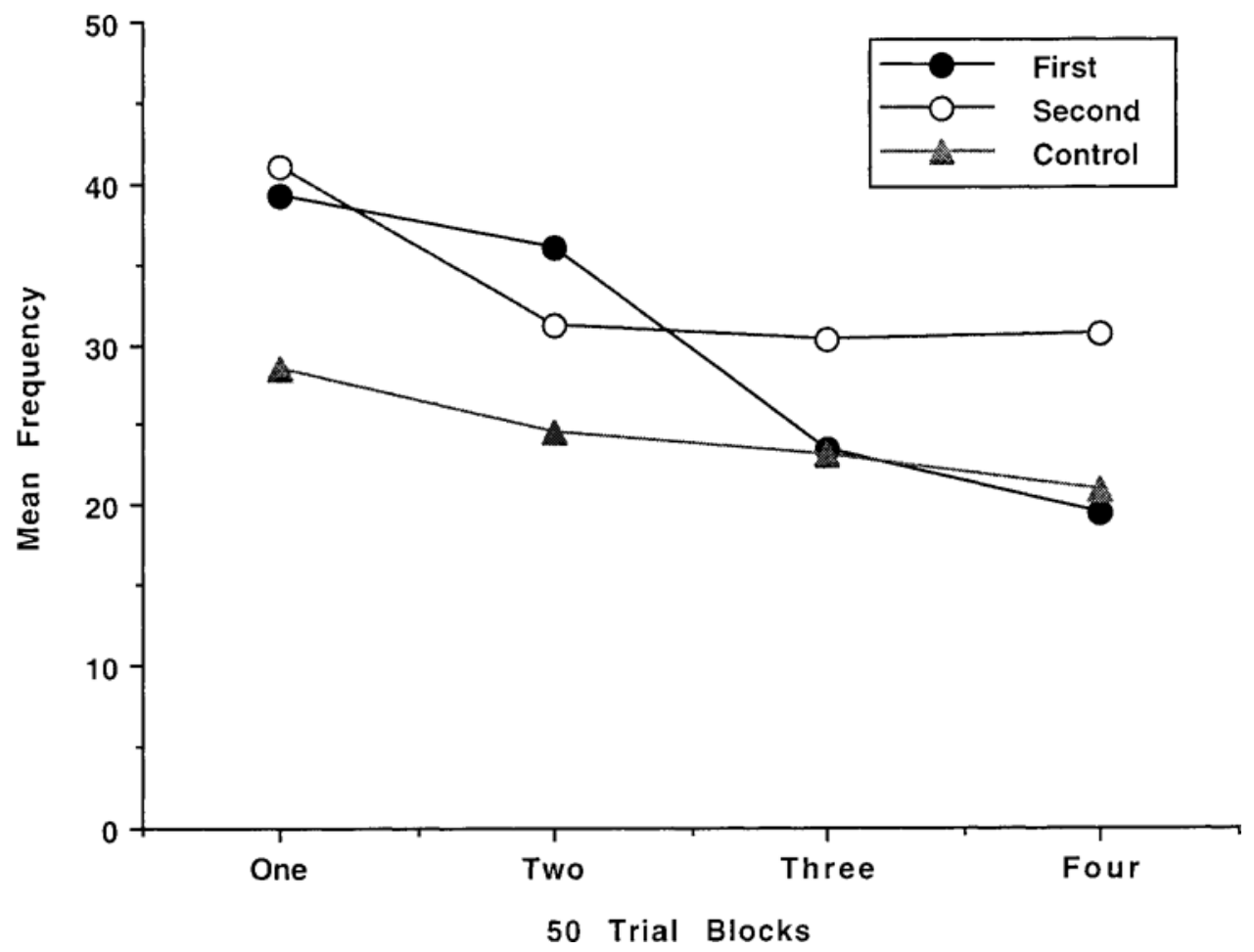

Figure 2. Mean frequency of different paths during (first data point) the lag25 contingency for the first and second groups and between the 51st and the 100th reinforced trials for the control group and during the next three blocks of 50 reinforced trials. Filled circles indicate responding by the first group, unfilled circles by the second, and triangles by the control groups. 


\section{Discussion}

Introducing the $\operatorname{lag} 25$ requirement at different times had two effects, immediate and sustained. The immediate effect was the same in both lag groups: No matter when the requirement was introduced, variability increased. The sustained effect differed, depending on when the lag was introduced: Sustained variability levels were higher if it occurred during the second block than if it was introduced at the start of the experiment (first) or was never introduced (control).

Variability can arise from doing a variety of old responses and/or through the induction of new behavior. The lag contingencies affect both classes of behavior. In the second group, the greater sustained variability was composed of both a larger variety of old responses and a greater number of new responses than was present in the other two groups. In the final block of trials, between $40 \%$ and $55 \%$ of the paths in all the groups were new ones. Thus, all the variability levels in this task, whether lower or higher, involved a mix of old and new paths.

\section{EXPERIMENT 2}

Experiment 1 supported two ideas suggested by Stokes et al. (1999): first, that there is an optimal period or window during which variability levels are acquired, and second, that this period occurs early, but not at the beginning of learning a novel task. Experiment 2 was designed to further examine the width of the window and to ensure that its effects were not specific to the task used in Experiment 1.

To these ends, the pyramid game in Experiment 2 had fewer possible paths $(32$ vs. 1,024). The lag25 contingency was introduced at a greater number of different points in training and lasted for a shorter period of time. Three different groups were exposed to the lag 25 contingency during the first, second, or fourth block of 25 trials. A fourth, control group never experienced the lag contingency.

If high, sustained variability depends on requiring high variability shortly after acquisition begins, the groups exposed to the lag25 contingency during the second and/or fourth block of 25 trials should be more variable than the group exposed to it sooner.

\section{Method}

Participants. Forty female Barnard undergraduates participated as part of a demonstration experiment in a learning laboratory.

Apparatus and Stimuli. The apparatus was the same as that in Experiment 1. The stimulus was a 5-pyramid, that required five presses on the right and left directional keys to move the white start box from the top to one of the orange triangles at the bottom. There are 32 different paths in this size pyramid.

Procedure and Analysis. The participants were assigned to one of four groups (first, second, fourth, or control), as is shown in Table 1. The data were divided into blocks. In each block, 25 reinforcers were delivered. Since incorrect paths were possible during the lag25 contingency, more than 25 trials might be necessary to earn the 25 reinforcers. For purposes of analysis, only the last 25 trials in each block were included. Variability was assessed by examining the number of different paths (five press sequences) taken through the pyramid in a given block. Number different refers simply to how many of the total possible paths were taken in a block. A significance level of $p<.05$ was used.

All the groups earned a total of 175 points. For the lag groups, the initial block was the one in which the lag25 contingency was in effect. The next three blocks, in which no variability requirement was in effect, were also analyzed. The control group was matched to the second group, so the four blocks for this group began on the 26th reinforced trial. In all other details, the procedure and analyses were identical to those in Experiment 1.

\section{Results}

Figure 3 presents mean number of different paths during the four successive 25-reinforcer blocks. The twoway ANOVA showed main effects of group $[F(3,36)=$ $4.25, p<.01]$ and block $[F(3,34)=22.89, p<.01]$ and a significant group $\times$ block interaction $[F(9,108)=2.29$, $p<.05]$. For Block 1, LSD tests showed that the control group was less variable than the three lag groups (for all comparisons, $p=.01$ ), which were not significantly different from each other during the lag25 requirement ( first vs. second, $p=.88$; first vs. fourth, $p=.08$; second vs. fourth, $p=.07)$. In considering only the data from the three lag groups, the group $\times$ block interaction was not statistically significant $[F(6,52)=1.02, p=.43]$. However, by Block 4, the second group was more variable than all the other groups (second vs. first, $p=.01$; vs. fourth, $p=.01$; vs. control, $p=.05)$.

To make sure that these results did not follow from the group differences prior to the lag manipulation, number of different paths and percentage of reinforced trials were compared in the three groups that started training without the lag contingency in effect. For the three groups that began without the lag requirement, there was no significant difference during the first 25 reinforced trials $[F(2,27)=1.301, p=.209]$. Group means were the following: control, 11 paths; second, 12 paths; fourth, 10 paths. These groups were all rewarded $100 \%$ of the time during the first 25 trials.

To see whether there was any differential sensitivity to the lag contingency, performance during lag25 was compared in the relevant groups. The LSD tests showed that mean number of different paths during the lag requirement did not differ between the first (17), second (17.2), and fourth (14.2) groups (first vs. second, $p=.88$; first vs. third, $p=.08$; second vs. fourth, $p=.07)$. However, there was a difference in percentage of reinforced trails during the whole block $[F(2,27)=5.289, p<.02]$. The first group (50.2\%) had a higher percentage than the second $(41.7 \%)$ or the fourth $(38 \%)$ groups. As would be expected from this pattern of differences in percentage of reinforced trials, there was also a significant difference in total trials $[F(2,27)=6.993, p<.01]$. Number of trials decreased from the fourth to the second to the first groups: Their respective means were 66.1, 58.5, and 48.7.

\section{Discussion}

The results of Experiment 2 extend those of Experiment 1 by showing that reinforcing variability either be- 


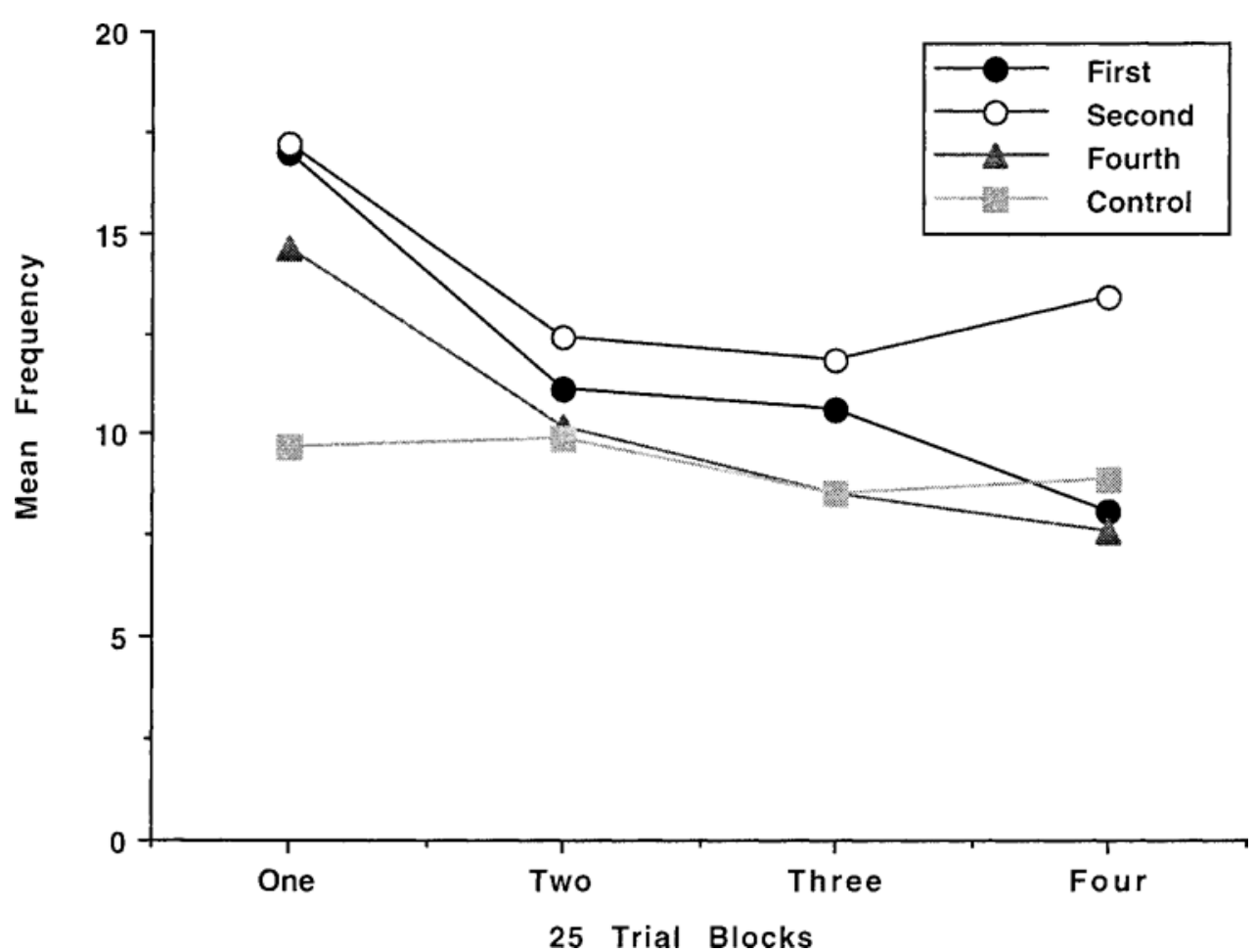

Figure 3. Mean frequency of different paths during (first data point) the lag25 contingency for the first and second groups and between the 26th and the 50 th reinforced trials for the control group and during the next three blocks of 25 reinforced trials. Filled circles indicate responding by the first group, unfilled circles by the second, triangles by the fourth, and squares by the control groups.

fore or after the optimal period does not sustain relatively high variability levels: There is a window in the acquisition process during which sustained performance levels appear to be set. The group experiencing lag 25 shortly after the start of training (second) was more variable than either the control group or the groups presented with the same requirement earlier (first) or later (fourth).

Although there were differences in reinforcement rate during lag25, the most variable (second) group did not differ on this measure from the least variable (fourth). We will return to this issue in the General Discussion section.

The task in the second experiment had a small number of possible paths (32), as compared with Experiment 1 (1,024 paths). There were far fewer new sequences that could be emitted in Experiment 2, and by the last block, these accounted for a very low percentage of response sequences (control, $3.2 \%$; first, $0.4 \%$; second, $1.6 \%$; fourth, 0). Consequently, variability differences in this experiment arose from differences in the variety of old paths, not from the induction of new behaviors.

\section{GENERAL DISCUSSION}

\section{Findings}

The present experiments provide an additional demonstration of the immediate effects of explicitly reinforcing variability (Machado, 1992, 1997; Page \& Neuringer,
1985; Stokes, 1999a). In both experiments, variability levels reliably increased during the lag 25 contingencies.

The results also show that if high variability contingencies are introduced shortly after task acquisition, they have sustained effects, continuing to affect performance after the contingencies are removed. Higher variability was maintained in the groups (second) that experienced the explicit high variability requirement shortly after task acquisition. Lower variability in later performance was observed in the groups never reinforced for high variability (control) and in those reinforced for high variability immediately (first) or later (fourth, Experiment 2) in training.

\section{Hypotheses}

An optimal period for setting variability levels. Stokes et al. (1999) suggested that sustained variability levels are acquired during an early critical or optimal period, during which these levels are differentially reinforced. Optimal here refers not to a specific period of time, but rather to a sequence of events.

High sustained variability levels seem to follow from (1) an initial period of reinforcement, followed by (2) an early change in criterion that results in lower reinforcement and (3) an increase in variability that helps satisfy the new criterion. Since meeting a novel criterion reinstates reward, aspects of responding that accomplish 
this—including increased variability—should be selected and maintained. The second groups experienced this sequence. They were initially successful (100\% reinforcement). When the lag 25 requirement was introduced, reinforcement decreased (following $78 \%$ of the sequences in Experiment 1 and $42 \%$ in Experiment 2), and variability increased. When the lag requirement was removed, this more variable performance resulted in higher reinforcement $(100 \%)$. We hypothesize that all three steps are necessary to produce high variability and that the steps must occur shortly after the start of training.

Lower variability levels appear to be maintained when these steps occur too late (fourth group, Experiment 2) or not at all, as is the case when initially low levels accompany successful early performance (control groups) or initially high levels are not consistently reinforced (the first groups).

An optimal period for reinforcement density. As was discussed in the introduction, there is considerable evidence that variability is greater during partial than during continuous reinforcement (e.g., Eckerman \& Lanson, 1969; Tatham et al., 1993). The present data provide no way of ruling out the possibility that what is important during our hypothetical optimal period is the density of reinforcement. For example, in Experiment 2, there was no difference in reinforcement during lag 25 for the groups highest (second) and lowest (fourth) in variability at the end of the experiment. This shows that partial reinforcement per se is not sufficient to sustain high levels of variability. However, it does not rule out the possibility that partial reinforcement during an optimal period is what generates the sustained effect.

An optimal period for forming a problem representation. Another way to conceptualize the optimal period involves construction of a problem representation or problem space, defined as the way a problem is represented by its solver (Newell \& Simon, 1972). For variability levels to be sustained in a particular task, they must be incorporated into the problem space of that task. An important part of a problem space is its operators. Operators are condition-action rules, identifying which response (the action) in a particular situation (the condition) leads to the goal. Condition-action rules have the form, "If this condition, then this action."

Operators leading to the same goal are organized in default hierarchies (Holland, Holyoak, Nisbett, \& Thagard, 1987). The default operator is the one with the most general condition (in the present experiments, this could be, "If playing the pyramid game, then press any key 10 times") and the greatest strength, meaning that it has been the most successful rule for reaching the goal in the past. The other operators in the hierarchy are exceptions to the default. That is, they have more specific conditions (e.g., "If playing the pyramid game and repeating the last path is unsuccessful, then alternate between keys when pressing") that override the default when those conditions are present.
If a certain amount of experience or evidence is necessary for a default representation to be established, very early experience may not influence later performance. However, once a default representation is formed, changed conditions will result in the acquisition of exception rules that are used when the default does not work. This line of thinking suggests two things: first, that the optimal period ends when the default rule is acquired, and second, that it may be elastic, its length dependent on the accumulation of evidence needed to establish it.

If the first groups (Experiments 1 and 2) acquired their default rules after the lag requirement was relaxed, there would be no sustained effect of early exposure to the variability contingency. If the second groups formed their default while the lag requirement was present, their initial representations might well incorporate high variability (e.g., "If the pyramid game, then be variable in the ways you move from the top to the bottom of the pyramid"). Finally, if the fourth group (Experiment 3 ) had already acquired a low variability default rule when the participants encountered the lag requirement, they would have acquired an exception rule to override the default when - and only when - a high variability requirement was in effect. When the requirement reverted to its initial lower level, reversion to the initial, less variable, default rule would occur.

Although not providing proof of these hypotheses, the participants did tell us how they earned points. Their accounts indicate that different groups, in fact, conceptualized the problem in different ways. In the highly variable second groups, 60\% (Experiment 1) and 70\% (Experiment 2) mentioned varying or doing different patterns. In the less variable groups, these responses were given by only $10 \%$ (Experiment 1) and 20\% (Experiment 2 ) of the control and first groups and by $10 \%$ of the fourth group (Experiment 2).

\section{Conclusions and Caveats}

By imposing identical variability requirements at different points in training, for different lengths of time, and with different numbers of possible responses, the present study expands our knowledge of when and how early training affects variability levels in later task performance. It supports the hypothesis that there is an optimal period in skill acquisition, during which particular sequences of events-which include increased variability leading to success-set default variability levels for a task or a domain. Since we have not used a wide range of tasks or training procedures, we must be cautious in our conclusions.

One caveat is that it may not be necessary to start without a lag requirement in order to sustain high variability. For example, Stokes (1999a) showed that a group exposed to a high lag contingency at the start of training and progressing to lower lag requirements (25 to 10 to 2 to 0 ) was more variable at each lag than a group that progressed in the opposite direction. A second is that different tasks may have different optimal periods. In the 
present study, the variability levels/default rules were acquired sooner in Experiment 2 than in Experiment 1. This difference may have been due to the relative difficulty of the two tasks or to the number of possible responses.

\section{Implications}

To fully understand the effects of rewarding variability, three things must be considered: the immediate effects of an explicit variability contingency, the sustained effects of that contingency, and the transfer of those effects to a new situation

The present study expands our knowledge by showing that immediate effects are sustained only if they occur at a particular point in training. This has important implications for learning and problem solving, because high variability is often associated with positive learning outcomes. With verbal as well as motor skills, consistent training on a single task results in more rapid acquisition on that task than does variety training, which involves practice on a number of similar tasks (Lai \& Shea, 1998; Schmidt $\&$ Bjork, 1992). However, variety training leads to greater retention and better transfer to novel problems than does consistent practice on a single task (Lai \& Shea, 1998; Schmidt \& Bjork, 1992). Variability is even sometimes associated with faster initial learning in traditional academic subjects, such as math (Goldin-Meadow, 1997; Siegler \& Jenkins, 1989).

What about transfer effects? If a child is more variable in writing than in math because she learned how to write or add, and how differently to do each one, then variability levels-like skills-should not transfer between domains. Indirect support for this idea comes from the literature on creativity and divergent thinking programs: The effects of variability training appear to be limited to the training domain or context (Baer, 1994). However, there is evidence that variability levels do sometimes transfer across domains. Children required to be variable on either an initial art or verbal task were more variable both on that task and on the alternate one than were children not exposed to the early variability requirement (Eisenberger \& Armeli, 1997; Funderbunk, 1977).

Of course, there are situations in which high variability is undesirable. Think about the accuracy required in performing laser surgery on the eye or monitoring nuclear reactor plants. In these cases, early training protocols should be designed to select low levels of variability. Such protocols include using precise instructions that are completely spelled out (Hackenberg \& Joker, 1994; Joyce \& Chase, 1990; Stokes et al., 1999) or requiring consistent rather than variable practice (Lai \& Shea, 1998; Schmidt \& Bjork, 1992). For low variability performance, the present study adds the suggestion that alternate ways of doing tasks be introduced only after initial learning is complete.

\section{REFERENCES}

Alibali, M. W., \& Goldin-Meadow, S. (1993). Gesture-speech mismatch and mechanisms of learning: What the hands reveal about a child's state of mind. Cognitive Psychology, 25, 468-523.
ANTONITIS, J. J. (1951). Response variability in the white rat during conditioning, extinction, and reconditioning. Journal of Experimental Psychology, 42, 273-281.

Atwood, M. E., \& Polson, P. G. (1976). A process model for water jar problems. Cognitive Psychology, 8, 191-216.

BAER, J. (1994). Divergent thinking is not a general trait: A multidomain training experiment. Creativity Research Journal, 7, 35-46.

BOULANGER,B. (1990). La variabilite comportementale: Une approache developpementale chez l'humain. Unpublished doctoral dissertation. Université de Liege, Faculté de Psychologie et des Sciences de l'Education.

Duncan, C. P. (1958). Transfer after training with single versus multiple tasks. Journal of Experimental Psychology, 55, 63-72.

ECKerman, D. A., \& LANson, R. N. (1969). Variability of response location for pigeons responding under continuous reinforcement, intermittent reinforcement, and extinction. Journal of the Experimental Analysis of Behavior, 12, 73-80.

EISENBERGER, R (1992). Learned industriousness. Psychological Review, 99, 248-267.

Eisenberger, R., \& Armeli, S. (1997). Can salient reward increase creative performance without reducing intrinsic creative interest? Journal of Personality \& Social Psychology, 72, 704-714.

FunderbunK, F. R. (1977). Reinforcement control of classroom creativity. In T. Brigham, R. Hawkins, J. W. Scott, \& T. F. McLaughlin (Eds.), Behavior analysis in education: Self-control and reading (pp. 197-204). Dubuque, IA: Kendall/Hunt.

Goldin-Meadow, S. (1997). When gestures and words speak differently. Current Directions in Psychological Science, 6, 138-143.

Goldin-Meadow, S., Nusbaum, H. C., Garber, P., \& Church, R. B. (1993). Transitions in learning: Evidence for simultaneously activated strategies. Journal of Experimental Psychology: Human Perception \& Performance, 19, 92-107.

Graham, T., \& Perry, M. (1993). Indexing transitional knowledge. Developmental Psychology, 29, 779-788.

HACKenberG, T. D., \& JoKer, V. R. (1994). Instructional versus schedule control of humans' choices in situations of diminishing returns. Journal of the Experimental Analysis of Behavior, 62, 367-383.

Holland, J. H., Holyoak, K. J., Nisbett, R. E., \& Thagard, P. R. (1987). Induction: Processes of inference, learning, and discovery. Cambridge, MA: MIT Press.

Holman, J., Goetz, E. M., \& BaEr, D. M. (1977). The training of creativity as an operant and an examination of its generalization characteristics. In B. C. Etzel, J. M. LeBlanc, \& D. M. Baer (Eds.), New developments in behavioral research: Theory, method and applications (pp. 441-471). Hillsdale, NJ: Erlbaum.

JAnos, P. M., \& Robinson, N. M. (1985). Psychosocial development in intellectually gifted children. In F. D. Horowitz \& M. O'Brien (Eds.), The gifted and talented: Developmental perspectives (pp. 149-196). Washington, DC: American Psychological Association.

Joyce, J. H., \& ChASE, P. N. (1990). Effects of response variability on the sensitivity of rule-governed behavior. Journal of the Experimental Analysis of Behavior, 54, 251-262.

KeIL, F. C. (1984). Mechanisms of cognitive development and the structure of knowledge. In R. J. Sternberg (Ed.), Mechanisms of cognitive development (pp. 81-100). New York: Freeman.

KLAHR, D. (1984). Transition processes in quantitative development. In R. J. Sternberg (Ed.), Mechanisms of cognitive development (pp. 101140). New York: Freeman.

LAI, Q., \& ShEA, C. (1998). Generalized motor program (GMP) learning: Effects of reduced frequency of knowledge of results and practice variability. Journal of Motor Behavior, 30, 51-59.

Luchins, A. S. (1942). Mechanization in problem-solving: The effects of Einstellung. Psychological Monographs, 56 (Whole No. 248).

Machado, A. (1992). Behavioral variability and frequency-dependent selection. Journal of the Experimental Analysis of Behavior, 52, 155-166.

MACHADO, A. (1997). Increasing the variability of response sequences in pigeons by adjusting the frequency of switching between two keys. Journal of the Experimental Analysis of Behavior, 68, 1-25.

Maltzman, I. (1960). On the training of originality. Psychological Review, 67, 229-242.

MoxLEy, S. E. (1979). Schema: The variability of practice hypothesis. Journal of Motor Behavior, 11, 65-70. 
Neuringer, A. (1992). Choosing to vary and repeat. Psychological Science, 3, 246-250.

Neuringer, A. (1993). Reinforced variation and selection. Animal Learning \& Behavior, 21, 83-91.

Newell, A., \& Simon, H. A. (1972). Human problem solving. Englewood Cliffs, NJ: Prentice-Hall.

Page, S., \& Neuringer, A. (1985). Variability is an operant. Journal of Experimental Psychology: Animal Behavior Processes, 11, 429-452.

Pryor, K. W., HaAg, R, \& O'Reilly, J. (1969). The creative porpoise: Training for novel behavior. Journal of the Experimental Analysis of Behavior, 12, 653-661.

Root-Bernstein, R. S., Bernstein, M., \& Garnier, H. (1995). Correlations between avocations, scientific style, work habits and professional impact of scientists. Creativity Research Journal, 8, 115138.

Royce, J. (1898). The psychology of invention. Psychological Review, 5, 113-144.

Ryan, B. A., \& Winston, A. S. (1978). Dimensions of creativity in children's drawings: A social-validation study. Journal of Experimental Psychology, 70, 651-656.

SALDANA, L., \& Neuringer, A. (1999). Is instrumental variability abnormally high in children exhibiting ADHD and aggressive behavior? Behavioural Brain Research, 94, 51-59.

Schmidt, R. A., \& BJork, R. A. (1992). New conceptualizations of practice: Common principles in three paradigms suggest new concepts for training. Psychological Science, 3, 207-217.

SchWARTZ, B. (1982a). Failure to produce response variability with reinforcement. Journal of the Experimental Analysis of Behavior, 37, 171-181.

SchWARTZ, B. (1982b). Reinforcement-induced behavioral stereotypy: How not to teach people to discover rules. Journal of Experimental Psychology: General, 111, 23-59.

Shea, J. B., \& Morgan, R. L. (1979). Contextural interference effects on the acquisition, retention, and transfer of a motor skill. Journal of Experimental Psychology: Human Learning \& Memory, 5, 179-187.
SIEGLER, R. S. (1995). How does change occur: A microgenetic study of number conservation. Cognitive Psychology, 28, 225-273.

Siegler, R. S., \& Jenkins, E. (1989). How children discover new strategies. Hillsdale, NJ: Erlbaum.

Stokes, P. D. (1995). Learned variability. Animal Learning \& Behavior, 23, $164-176$.

StOKES, P. D. (1999a). Learned variability levels: Implications for creativity. Creativity Research Journal, 12, 37-45.

Stokes, P. D. (1999b). Novelty. In M. A. Runco \& S. R. Pritzker (Eds.), Encyclopedia of creativity (Vol. II, pp. 297-304). San Diego: Academic Press.

Stokes, P. D., \& Balsam, P. (1991). Effects of reinforcing preselected approximations on the topography of the rat's barpress. Journal of the Experimental Analysis of Behavior, 12, 349-373.

Stokes, P. D., Mechner, F., \& Balsam, P. O. (1999). Effects of different acquisition procedures on response variability. Animal Learning \& Behavior, 27, 28-41.

Tatham, T. A., Wanchisen, B. A., \& Hineline, P. N. (1993). Effects of fixed and variable ratios on human behavioral variability. Journal of the Experimental Analysis of Behavior, 59, 349-359.

Vogel, R, \& Annau, A. (1973). An operant discrimination task allowing variability of reinforced response patterning. Journal of the Experimental Analysis of Behavior, 20, 1-6.

Wallace, D. B., \& Gruber, H. E. (1989). Creative people at work: Twelve cognitive case studies. New York: Oxford University Press.

WeINER, H. (1969). Controlling human fixed-interval performance. Journal of the Experimental Analysis of Behavior, 12, 349-373.

Winner, E. (1996). Gifted children: Myths and realities. New York: Basic Books.

Wong, P. T., \& PeAcock, E. J. (1986). When does reinforcement induce stereotypy? A test of the differential reinforcement hypothesis. Learning \& Motivation, 17, 139-161.

(Manuscript received July 14, 1999;

revision accepted for publication March 3, 2000.) 